
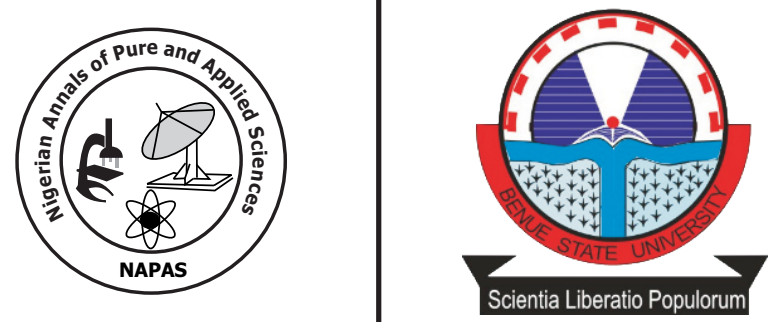

\title{
Passengers' Traffic Forecast of the Nigeria Airports using the Holt-Winters Additive Model
}

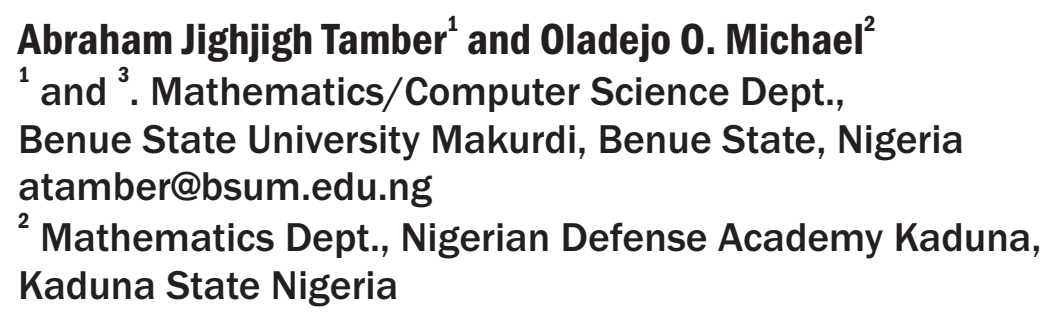

\begin{abstract}
This research work was carried out in response to the need for air transport facilities as a result of increase in Nigeria population.it was developed using the data of the Federal Airport Authority of Nigeria, which has a total number of 23 airports out of which four are international airports, seven are domestic airports and twelve are other domestic airports with the total number of 75,879,653 passengers between Jan. 2003 and Dec. 2011. The passengers' traffic of FAAN's data of 2003 to 2011 were collected and forecasted using the NCSS computer package to generate the Holt-Winters additive model with coefficient of determination, $R^{2}$ of $90.99 \%$ and the models were used to forecast for the years 2012 to 2019 using the models.
\end{abstract}

Keywords: Time series analysis, Nigeria Airports, Holt-Winters additive model, Passengers' traffic forecast 


\section{Introduction}

Transportation problems in Nigeria are enormous, especially with so many challenges on the highway, such as armed robbery attacks, insurgency and terrorism, which hinder the free flow of traffic of goods and services. However, its significance cannot be far-fetched from or beyond: economic purpose, social integration and spatial interaction (Adenira, Skanyio and Owoeye, 2018).

According to Anyanwu, Oaikhena, Oyefusi and Dimowo (1997), transportation system in Nigeria started as far back as precolonial era. The first form of transport was shanks pony (i.e. human foot), within this period, transportation facilities such as roads, railways, and air transport facilities were really non-existent with emphasis then on the bush path. However, Tim (2013) stated that, people eventually learnt to use animals such as donkeys, horses, camels e.t.c., i.e. animals were domesticated for transportation. As the years went by, different modes of transportation were invented and improved. With improvement, there are many modes of transportation. Each mode has a fundamental different technology, and requires a separate environment and also has its own infrastructure, vehicles and operations which often have unique regulations.

The main modes of transport in Nigeria are:
a. Air transport
b. Land transport which consist of:
i. Rail transport
ii. Road transport.
c. Water transport
d. Other modes of transport: these consist of:
i. Pipeline and pneumatic tubes transport
ii. Electronic transport
iii. Cable transport
iv. Space transport
v. Animals transport.

Although, all the modes of transportation play a significant role in the economic growth and development of Nigeria both directly and indirectly, this study address the forecast of the passengers' traffic of the air transport system in Nigeria. According to Murat (2014), income and population has increased and the structure of industry has changed, air transportation has grown significantly over the last years. Today, it is essential component of leisure and business related travelling, and thus of human connectivity and worldwide economical integration. According InfoGuide Nigeria (2020), the Federal Airports Authority of Nigeria (FAAN) is a federal government agency, set up to manage every commercial airport in the country, as well as making sure that, it provides services to both the airlines and the passengers in the airports. Nigeria has total number of four (4) international airports (Lagos, Abuja, Kano and Port Harcourt), seven (7) domestic airports (Calabar, Enugu, Jos, Kaduna, Maiduguri, Sokoto and Yola) and twelve (12) other domestic airports (Akure, Bauchi, Benin, Ibadan, Gombe, Ilorin, Katsina, Makurdi, Minna, Owerri, Warri and Zaria), summing up to 23 airport in Nigeria. At each airport records are kept daily, weekly and then compiled into monthly statistical report of passengers.

The research conducted by Travelstart (2016) revealed that, Nigerian airports lack facilities $(59 \%)$, general conduct of officers of forces such as Immigration, Port health, Customs (57\%) and careless handling of luggage $(44 \%)$ as the top pain points of travelling through Nigerian airports. Vos (2016) also reflected on the unfavourable conditions of the Nigerian airports as one of the worst on the continent. Similarly, CNN Travel (2016) ranked Port Harcourt as the worst airport in the world. Travelstart (2016) further suggested to FAAN that in order to improve on the Nigeria airports, the following facilities should be added or improve on: Wi-Fi, air conditioning, customer service and staff training. In view of these problems and the rapid growth in Nigeria population, there is need for FAAN to predict the passengers' traffic bearing in mind these problems.

Gelper, Roland and Christophe (2008) stated that Peter Winters generalized the Holt's linear method in 1960s to come up with a technique, called Holt-Winters method (Triple Exponential Smoothing). It is an extension of exponential smoothing designed for trended and seasonal time series. Holt-Winters smoothing is a widely used tool for forecasting business data that contain seasonality, changing trends and seasonal correlation. A seasonal equation is added to Holt's linear method equations. This is done in two ways, additive and multiplicative model. According to Makridakis and 
Wheelwright (1989), Holt-Winters model produces results similar to those of linear exponential smoothing but it has the extra advantage of being capable of dealing with seasonal data in addition to data that have trend. The authors furfigther explained that Winters' linear and seasonal exponential smoothing is based on three equations, each of which smooths a factor associated with one of the three components of the pattern: randomness, trend and seasonality in this respect it is similar to linear exponential smoothing which smooths for randomness and adjusted for trend, however, Winters' method includes an additional parameter to deal with seasonality.

Predicting the future has been one of the highly desired ambitions of individuals, organizations and even nations. The desire to forecast the future is as old as the human race. For instance, in the primitive society, a predictor may try to predict where the prey will run. In ancient times, people relied on prophets, soothsayers and crystals ball. During the last few decades, the study of air travel demand has attracted considerable attention from researchers, alternative methods have been used for modelling and forecasting air passengers demand such as the econometric models (Suryani, Chou and Chen 2010; Aderamo, 2010; Huber, 2010; Profillidis, 2012 and Scarpel 2013), time series models (Samagaio and Wolters 2010; Min, Kung and Liu 2010; Xie, Wang and Lai. 2014), artificial intelligence (Alekseev and Seixas, 2009; Kuo, Shiau and Chang 2012; Chen, Kuoa Chang and Wang 2012) and judgmental approaches and gravity models (Dennis, 2002; Grosche, Rothlauf and Heinzl 2007 and Sivrikaya and Tune, 2013). Today we have computers and with them an impressive ever-expanding array of quantitative capacities. According to Karlaftis, 2010 and Tsui, Balli, Gilbey and Gow 2014, the choice of any methodology is dependent on how successful a model can forecast air passengers' demand.

\section{Methodology}

The data for this work were collected from FAAN which has the total number of 23 airports with total number of $75,879,653$ passengers between Jan. 2003 and Dec. 2011. At each airport a records are kept daily, weekly and then compiled into monthly statistical report of passengers. Hence, a historical record is generated at any time ( $\mathrm{t}$ ) for a parameter to be used as input. The monthly records were used because, using the data on individual airport or daily or monthly records basis will not yield the expected result as some airport were shot-down for some reasons for a number of months, therefore, all operations at such airports were also closed.

The data from the target population (FAAN) see Table 1 were subjected to HoltWinters models. According to Makridakis and Wheelwright (1989), "one of the problems accompanying the use of Winters method is determining the values for $\alpha, \beta$ and $\gamma$ that will minimize MSE or MAD, the approach for doing this manually is trial and error. The search for the values is made by a grid approach where the results using different values for $\alpha, \beta$ and $\gamma$ are compared to find the combination that minimizes MSE or MAD. With today's computer statistical packages (Microsoft Excel, SPSS, NCSS, etc), finding the best values of $\alpha, \beta$ and $\gamma$ is no longer the problem".

Table 1: Airport Passengers' traffic data (2003-2011)

\begin{tabular}{llllllllll}
\hline Months & $\mathbf{2 0 0 3}$ & $\mathbf{2 0 0 4}$ & $\mathbf{2 0 0 5}$ & $\mathbf{2 0 0 6}$ & $\mathbf{2 0 0 7}$ & $\mathbf{2 0 0 8}$ & $\mathbf{2 0 0 9}$ & $\mathbf{2 0 1 0}$ & $\mathbf{2 0 1 1}$ \\
\hline JAN & 422087 & 769774 & 649381 & 573811 & 766533 & 870312 & 907734 & 1013162 & 1155534 \\
FEB & 368798 & 630439 & 651599 & 537053 & 605140 & 709612 & 833383 & 932974 & 1116266 \\
MAR & 409208 & 637620 & 703403 & 575451 & 663107 & 801311 & 881514 & 1009540 & 1258140 \\
APR & 397815 & 696343 & 723280 & 678026 & 611393 & 892009 & 1030886 & 1116548 & 1048730 \\
MAY & 432962 & 644540 & 700510 & 685223 & 624286 & 839736 & 970442 & 1106072 & 1217093 \\
JUN & 438920 & 603808 & 662364 & 692077 & 525647 & 847083 & 982455 & 1103273 & 1176033 \\
JUL & 389859 & 705917 & 690873 & 725483 & 722781 & 872444 & 1059254 & 1223256 & 1203799 \\
AUG & 501050 & 720943 & 786968 & 773118 & 776005 & 1027829 & 1112405 & 1297332 & 1305966 \\
SEP & 521221 & 704563 & 767004 & 718594 & 725295 & 935087 & 1061347 & 1278015 & 1212442 \\
OCT & 522837 & 656704 & 714077 & 774278 & 783811 & 868082 & 1220964 & 1241689 & 1369923 \\
NOV & 494596 & 634024 & 611318 & 676999 & 745221 & 1056987 & 1178374 & 1234545 & 1329764 \\
DEC & 556781 & 752477 & 649738 & 798082 & 860725 & 1109080 & 1287706 & 1425271 & 1358149 \\
\hline
\end{tabular}


According to Makridakis and Wheelwright (1989), Holt-Winters model is classified as either additive or multiplicative model, but in this research work, the additive model was used. The Additive Holt-winters model:

Initial:

$$
\begin{aligned}
& \mathrm{L}_{\mathrm{s}}=\frac{1}{s} \sum_{i=1}^{s} y_{i} \\
& \mathrm{~b}_{\mathrm{s}}=\frac{1}{s}\left[\frac{y_{s+1}-y_{1}}{s}+\frac{y_{s+2}-y_{2}}{s}+\cdots+\frac{y_{2 s}-y_{s}}{s}\right] \\
& \mathrm{S}_{\mathrm{s}}=y_{i}-L_{s}, \mathrm{I}=1, \ldots, \mathrm{s} \\
& \text { choose } 0 \leq \alpha \leq 1,0 \leq \beta \leq 1 \text { and } 0 \leq \gamma \leq 1 \\
& \text { Compute for } \mathrm{t}>\mathrm{s}: \\
& \quad \text { forecast } \mathrm{F}_{\mathrm{t}+1}=\mathrm{L}_{\mathrm{t}}+\mathrm{b}_{\mathrm{t}}+\mathrm{S}_{\mathrm{t}+1-\mathrm{s}}
\end{aligned}
$$

where,

$$
\begin{aligned}
& \text { level } L_{t}=\alpha\left(y_{t}-S_{t-s}\right)+(1-\alpha)\left(L_{t-1}+b_{t-1}\right) \\
& \text { trend } b_{t}=\beta\left(L_{t}-L_{t-1}\right)+(1-\beta) b_{t-1}, \\
& \text { seasonal } S_{t}=\gamma\left(y_{t}-L_{t}\right)+(1-\gamma) S_{t-s}
\end{aligned}
$$

Until no more observations are available and subsequent forecasts:

$\mathrm{F}_{\mathrm{n}+\mathrm{k}}=\mathrm{L}_{\mathrm{n}}+\mathrm{k} \mathrm{b}_{\mathrm{n}}+\mathrm{S}_{\mathrm{n}+\mathrm{k}-\mathrm{s}}$

Where:

Level: is the smoothed deseasonalized series.

Trend: is the general direction in which the graph of a time series appears to be going over a long interval of time.

Seasonal: is the identical or almost identical pattern that a time series appears to follow during corresponding months or quarters of successive years.

Makridakis and Wheelwright (1989) suggested that, for a time series, you select the Holt Winters algorithms with the smallest SSE or RMSE or MAPE and also stated the following specific measures of accuracy that can be used with a wide variety of methods:

i. Mean error

$$
\mathrm{ME}=\frac{\sum_{i=1}^{n} e_{i}}{n}
$$

ii. Mean absolute deviation

$$
\mathrm{MAD}=\frac{\sum_{i=1}^{n}\left|e_{i}\right|}{n}
$$

iii. Mean squared error

$$
\mathrm{MSE}=\frac{\sum_{i=1}^{n} e_{i}{ }^{2}}{n}
$$

iv. Standard deviation of error

$$
\mathrm{SDE}=\sqrt{\frac{\sum_{i=1}^{n} e_{i}^{2}}{n-1}}
$$

v. Percentage error

$$
\mathrm{PE}_{\mathrm{t}}=\frac{X_{t}-F_{t}}{X_{t}} 100
$$

vi. Mean percentage error

$$
\mathrm{MPE}=\frac{\sum_{i=1}^{n} \mathrm{PE}_{\mathrm{t}}}{n}
$$

vii. Mean absolute percentage error

$$
\mathrm{MPE}=\frac{\sum_{i=1}^{n}\left|\mathrm{PE}_{\mathrm{t}}\right|}{n}
$$




\section{Passengers' Traffic of Federal Airport Authority of Nigeria Analysis and Result}

The NCSS (Trier version) software was used to analyze the data of Table 1 above and the results are as shown below in Table 2:

Table 2: Winter's with additive seasonal adjustment.

\begin{tabular}{ll}
\hline Number of Rows & 96 \\
\hline Mean & 790413.1 \\
Coefficient of Determination $\left(\mathrm{R}^{2}\right)$ & 0.909908 \\
Mean Square Error & 4982623000 \\
Mean |Error| & 55432.17 \\
Mean |Percent Error| & 7.339669 \\
Alpha & 0.393743 \\
Beta & 0.01924684 \\
Gamma & 0.49491 \\
Intercept (a) & 1091395 \\
Slope (b) & 9233.029 \\
\hline
\end{tabular}

From Table 2 shows that, the additive model explains $90.99 \%$ of the variation in the passengers' traffic while the remaining $9.01 \%$ can only be explained chance. From Table 2 above, the additive forecast model is given as: $\mathrm{F}_{\mathrm{t}+1}=\mathrm{L}_{\mathrm{t}}+\mathrm{kb} \mathrm{b}_{\mathrm{t}}+\mathrm{S}_{\mathrm{t}+1-\mathrm{s}}$

$$
\begin{array}{rlr}
\text { But } \mathrm{L}_{\mathrm{t}} & =0.39374\left(\mathrm{y}_{\mathrm{t}}-\mathrm{S}_{\mathrm{t}-\mathrm{s}}\right)+0.60626\left(\mathrm{~L}_{\mathrm{t}-1}+\mathrm{kb}_{\mathrm{t}-1}\right) & 16 \\
\mathrm{~b}_{\mathrm{t}} & =0.01924684\left(\mathrm{~L}_{\mathrm{t}}-\mathrm{L}_{\mathrm{t}-1}\right)+0.98075316 \mathrm{~b}_{\mathrm{t}-1} & 17 \\
\mathrm{~S}_{\mathrm{t}} & =0.49491\left(\mathrm{y}_{\mathrm{t}}-\mathrm{L}_{\mathrm{t}}\right)+0.50509 \mathrm{~S}_{\mathrm{t}-1} & 18
\end{array}
$$

Forecast for 2012 to 2019 or Out of Sample Forecast

From Table 2, the model for relationship between the passengers' traffic and the period see equation 19 is used to forecast for the years 2012 to 2019 as depicted in figure 2 . Since the $\mathrm{R}^{2}$ (coefficient of determination) is very large $(0.90990$ or $91 \%)$, our model gives a good forecast and hence a good model is obtained.

\section{Model Accuracy}

A plot of the actual and forecasted values are shown in figure 1 of the additive HoltWinters model the plot of residual $\left(e_{t}\right)$ was made against time $(\mathrm{t})$ and plot appears to show a random behavior of the residuals indicating that there is no heteroscedasticity, thus there is no indication of the model's inadequacy, see figure 2. 


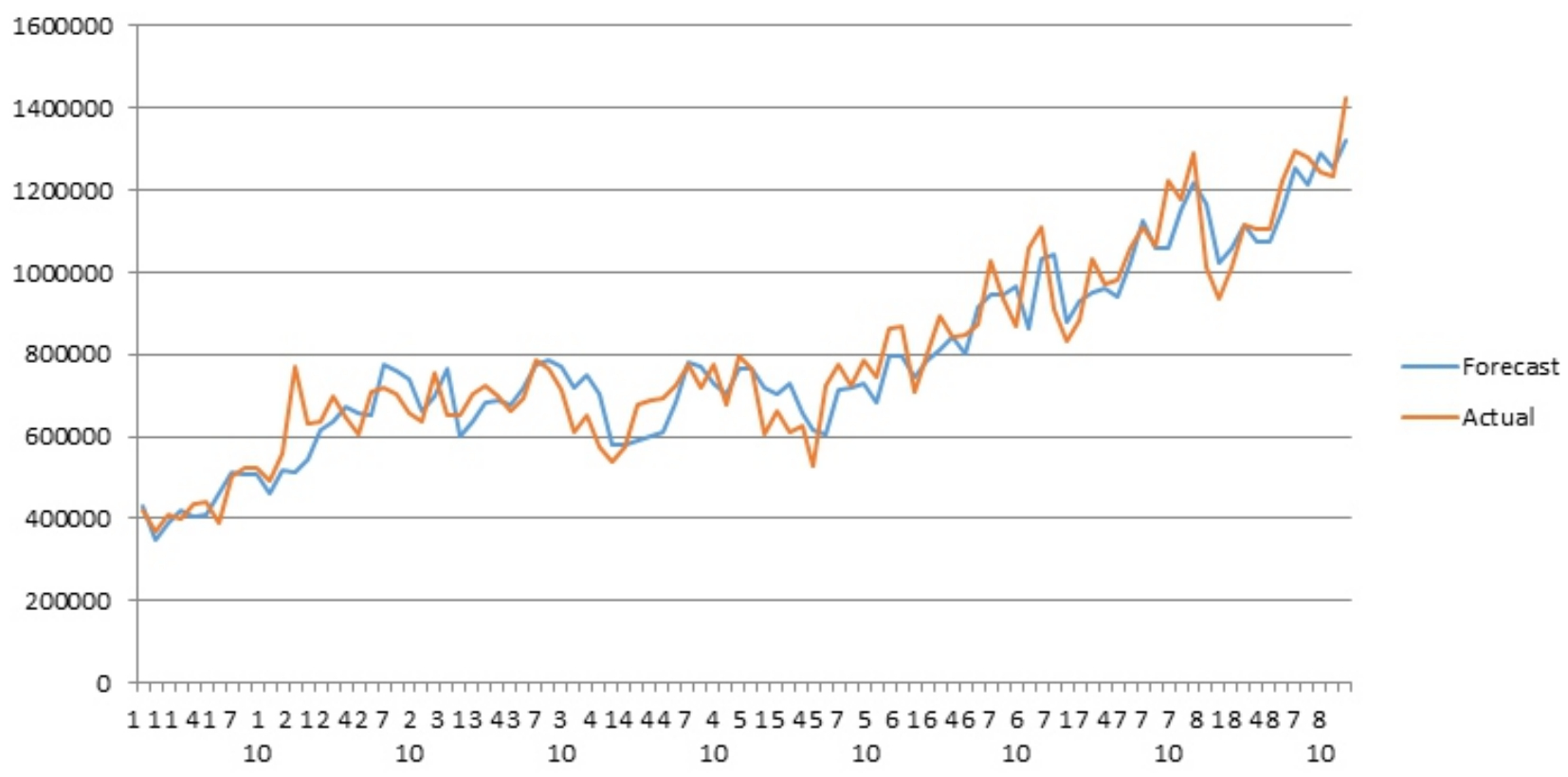

Fig 1: The plot of actual values and predicted values against time of Passengers traffic of Nigerian Airports for Additive Winters' model.

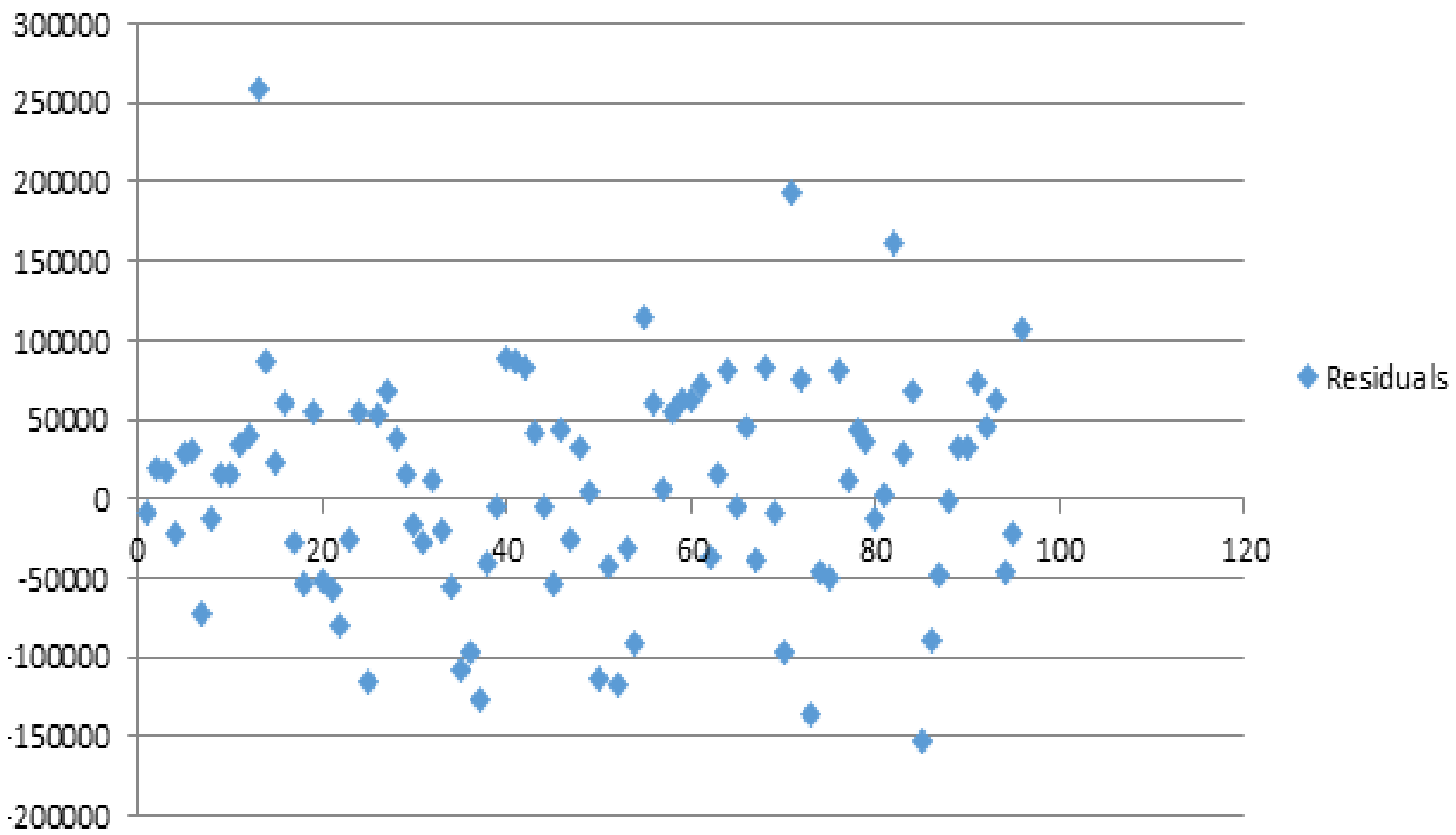

Fig 2: The plot of Residuals of Passengers traffic of Nigerian Airports for Additive Winters' model.

\section{Findings} work:

The following findings resulted from this

1. The additive Holt-Winters model was formulated.

2. The additive Holt-Winters model was used to forecast the FAAN passengers' traffic.

3. FAAN should use the additive HoltWinters model in forecasting their passengers' traffic.
4. Any data of this nature can be forecasted using additive Holt-Winters model.

\section{Recommendations}

Based on the work done so far on this research, one can make the following recommendations that:

1. The additive method of Holt-Winters model should be used to forecast the time series data of the passengers' traffic of the 
air transport.

2. The Federal Airports Authority of Nigeria adopts the additive method of HoltWinters model to predict the traffic of passengers she can expect for the next months or years (up to 20 years).

3. The Federal Airports Authority of Nigeria pays attention to the seasonal indexes in order to know the peak and low periods of the traffic of passengers.

4. Future researchers should consider individual airport time series data.

5. Any flaw identifiable from this work should be corrected by the future researcher.

\section{Summary and Conclusion}

Objectively, this study has been applied to all the laid down procedure to collect, analysis and interpret the data of passengers' traffic of the Federal Airports Authority of Nigeria. While the outcome of the forecasting technique of the time series has yielded a forecasting model: HoltWinters additive model for the passengers' traffic of Nigerian Airports. The Holt-Winters additive model yielded the good model to forecast the passengers' traffic of the FAAN.

\section{References:}

Adenira A. O., Skanyio O. A. and Owoeye A. S. (2018). Forecasting Methods for Domestic Air Passenger Demand in Nigeria. Journal of Applied Research on Industrial Engineering Volume 5.

Aderamo, A.J. (2010). Demand for air transport in Nigeria. Journal of Economics, (1) 1, 23-31.

Alekseev, K.P.G. and Seixas, J.M. (2009). A multivariate neural forecasting modeling for air transport - preprocessed by decomposition: a Brazilian application. Journal of Air Transport Management, 15, 212-216.

Anyanwu, J. C; Oaikhena, H., Oyefusi, A. and Dimowo, F. A. (1997). The Structure of the Nigerian Economy (1960-1977) Onitsha, Nigeria: Joanne Educational Publishers Ltd.

CNN Travel (2016). Business Traveler: What are the World's Worst Airposts for 2015? CNN Sans Cable NEW network, Turner Broadcasting System Inc. edition.cnn.com > travel > gallery > worlds-worst-airports2015
Chen, S.C., Kuoa, S.Y., Chang, K.W., and Wang, Y.T. (2012). Improving the forecasting accuracy of air passenger and air cargo demand: the application of backpropagation neural networks. Transportation Planning and Technology, (35): 3, 373-392.

Dennis, N. P. S. (2002). Long-term route traffic forecasts and flight schedule pattern for a medium-sized European airport. Journal of Air Transport Management, 8(5), 313324.

Gelper S., Roland F. and Christophe C. (2008), Robust Forecasting with Exponential and Holt - W inters S moothing. https://lirias.kuleuven.be/bitstream

Grosche, T., Rothlauf, F., and Heinzl, A. (2007). Gravity models for airline passenger volume estimation. Journal of Air Transport Management, 13, 175-183.

Karlaftis, M. G. (2010). Critical Review and Analysis of Air-Travel Demand: Forecasting Models. In L. Weigang, A. Barros, and I.R. Oliveira (Eds.), Computational Models, Software Engineering, and Advanced Technologies in Air Transportation: Next Generation Applications (pp. 72-87). Hershey, PA: IGI Global.

Huber, H. (2010). Statistical mechanics for analytic planning: an application to domestic air traffic in China. Transportation Planning and Technology, 33(7), 551-567.

InfoGuide Nigeria (2020). 6 Functions of Federal Airports Authority of Nigeria (FAAN)https://infoguidenigeria.com/fed eral-airports-authority-nigeria/

Kuo, S. Y., Shiau, L. C., and Chang, Y. P. (2012). Air transport demand forecasting in routes network by artificial neural networks. Journal of Aeronautics Astronautics and Aviation, 42, 67-72.

Makridakis S. C. and Wheelwright S. C. (1989), Forecasting Methods for Management, John Wiley and Sons Inc.

Min, J. C. H., Kung, H. K., and Liu, H. S. (2010). Interventions affecting air transport passenger demand in Taiwan. African Journal of Business Management, 4(10), 2121-2131.

Murat C. (2014). Building Proper Forecast Model for Daily Air Passenger Demand: A 
Case Study Antalya International Airport. International Antalya Hospitality Tourism and Travel Research Proceeding, Porto Bello Hotel Antalya, Turkry, $9^{\text {th }}$ to $12^{\text {th }}$, December, 2014.

Profillidis, V. A. (2012). An ex-post assessment of a passenger demand forecast of an airport. Journal of Air Transport Management, 25, 47-49.

Scarpel, R. A. (2013). Forecasting air passengers at São Paulo International Airport using a mixture of local experts' model. Journal of Air Transport Management, 26 (2013), 35-39.

Samagaio, A., and Wolters, M. (2010). Comparative analysis of government forecasts for the Lisbon Airport. Journal of Air Transport Management, 16, 213217.

Sivrikaya, O., and Tunç, E. (2013). Demand Forecasting for Domestic Air Transportation in Turkey. The Open Transportation Journal, 7, 20-26.

Suryani, E., Chou, S. Y., and Chen, C. H. (2010). Air passenger demand forecasting and passenger terminal capacity expansion: A system dynamics framework. Expert Systems with Applications, 37 , 2324-2339.

Tim, L (2013). A BRIEF HISTORY of T R A N S P O R T A T I O N www.localhistories.org

Travelstart (2016). Survey Reveals Nigerians Airport Pains. Travelstart online Travel O p e rat i o n s t y L t d. www.travelstart.com.ng

Tsui, W. H. K., Balli, H. O., Gilbey, A., and Gow, H. (2014). Forecasting of Hong Kong airport's passenger throughput. Tourism Management, 42, 62-76.

Vos G. (2016). SA's Airports Best in Africa, and $\mathrm{D}$ o A v i o d L a g o s . http://www.bdlive.co.za/archive/

Xie, G., Wang, S., and Lai, K. K. (2014). Shortterm forecasting of air passenger by using hybrid seasonal decomposition and least squares support vector regression approaches. Journal of Air Transport Management, 37 (2014), 20-26. 